\title{
The Variety of HPST Scholarship
}

\author{
Kostas Kampourakis ${ }^{1}$
}

Published online: 17 November 2017

(C) Springer Science+Business Media B.V., part of Springer Nature 2017

It is well known that Science \& Education publishes a variety of empirical and theoretical articles, many of which are occasionally quite different from those of the "mainstream," science education research. In our journal, we like to publish theoretical articles that are special, perhaps unconventional, and that may open new horizons for research. At the same time, we value the conclusions of robust empirical research. As a result, the issues of Science \& Education usually include articles of both kinds, which we find that appeal to a wide variety of readers - a result of the variety of HPST scholarship.

At times, this variety is stunning. I recently had to make a decision about how to group several different articles on different topics that had been accepted for publication in the journal. Considering this, as well as practical issues, I decided to have them published in print all together in the present triple issue. This is the first time during my editorship that I am publishing a triple issue, and I hope that it will be seen as an exemplar point of reference on the kinds of articles published in Science \& Education. The topics of these articles include risk, models, scientism, the ethical responsibility of teachers, students' epistemologies, nature of science and art, nature of science and learners' characteristics, teaching natural selection, and education values in teaching mathematics. I hope that readers will find these articles useful and will appreciate their variety.

This variety is also reflected in the book reviews that we publish (not only in this issue, but generally speaking). The books reviewed come from a variety of fields: science education, history of science, philosophy of science, and science itself. An interdisciplinary field like HPST requires scholars who are able to keep up with developments in the related fields. Yet, this is very difficult to do, and it is even more difficult to be able to read the numerous books published. Here is the value of book reviews: on the one hand, readers come to know about books that they may have been unaware of; on the other hand, they can read the evaluation of an expert reviewer and decide whether they will read the book themselves or not. Both contributions of book reviews are very important.

Kostas Kampourakis

Kostas.Kampourakis@unige.ch

1 Section of Biology and IUFE, University of Geneva, Geneva, Switzerland 
Therefore, we hope that readers appreciate this variety and we look forward to your contributions that will further augment it. I must note that Science \& Education publishes empirical and theoretical articles that are informed by the HPS scholarship and that have explicit and clear implications for science (and relevant mathematics) teaching and learning. We look forward to reading your work!

\section{Compliance with ethical standards}

Conflict of interests The author declares no conflict of interest. 